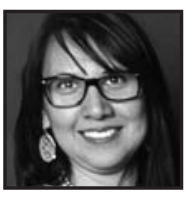

\title{
A Whisper of True Learning
}

\author{
Belinda C. Daniels
}

\section{ABSTRACT}

In this article, I describe my journey to develop my Indigenous teacher identity, and I explore constructs that either diminished or enhanced my identity development within the experiences of formal and non-formal learning. I narrate a pivotal moment in my teaching career that made me question what kind of teacher I was going to be. It was a "whisper of true learning" that awakened the depths of my nêhiyâw identity. It made me realize that I had forgotten who I was and, at the same time, that it was my responsibility to remember where I came from for the benefit of my students.

\section{A Whisper of True Learning}

\section{Beginning as a Teacher}

n my second year of teaching at a typical mainstream high school in western Canada, I taught History, English, and the Cree language. The school was large and overcrowded, as trailers in the form of portable classrooms had to be installed to the yellow brick structure. The school had a theatre, two gyms, a cafeteria, a chapel, a large industrial wood working room, and numerous classrooms-and a population of well over 1,300 students and 100 or so teachers.

My classroom was on the second floor, and I shared it with the science teacher. The lights were bright white fluorescent and the only natural lighting came from the back room, through a door if it was opened. On the other side of that door was a storage room filled with plants, along with science chemicals, glass in various-sized beakers, and so on. I had four or five rows of desks, too many for the amount of students I had, 
which made the room look empty. I often stood at the front of the room where a platform was built a foot higher than the rest of the floor plan. The floor was made of white tile and the walls were either mainly empty cupboards or empty bulletin boards.

As a beginning teacher, I often wrote notes right out of the textbook because I did not know any better when it came to second language instruction, much less the teaching of an Indigenous language. It is also important to note that I was not a fluent speaker of the Cree language/nêhiyawêwin.' I could barely pronounce any of the long Cree words properly, much less confidently. It was the mentality at the time that, because I was Indigenous and grew up on a Reserve, I should know and speak some Cree. Although a good idea initially, it added pressure to my teaching assignment, not to mention frustration and stress as a beginning teacher.

This school had students enrolled from upper- and middle-class families. The student population at the time was mostly Euro-Canadians and a small percentage of new immigrant families. I was the only visible Indigenous, nêhiyâw teacher on staff, although there were a couple of other teachers who were of Métis and Dakota heritage who did not grow up on the Reserve. The irony of my teaching assignment was that this was the high school where I received my secondary education and from which I had graduated previous years before. Not much had changed at this high school in regard to teaching practices since I had left it as a student. Some of the same teachers who taught me were still there, teaching the same subjects.

When I think back to being a student, I realize I still suffer from the emotional scars I endured, such as discrimination and the feeling of not belonging there. I do not think those feelings ever go away, no matter how much time has passed. My urban high school years were not filled with joyful memories, and not at all like you see in movies like Pretty in Pink or The Breakfast Club. They were filled more with awkwardness, isolation, and alienation. I realize now that this is not an uncommon way to feel as an Indigenous student. As Gebhard (2013) affirms through research, "Indigenous students report frequent incidents of overt racism in school and often feel lonely and isolated while attending school" (Briarpatch Magazine: http://briarpatchmagazine.com/articles/ view/pipeline-to-prison). Other factors may have also contributed to the feelings of isolation and alienation I experienced, as I did not go to elementary school with all the other students from the local feeder schools and I did not sign up for any of the team sports because of the self-consciousness I felt about my body. Worse, perhaps, was it the color of my skin? Was it the fact that schools were not made initially or intentionally for people like me, since the beginning of mainstream or Eurocentric education? "Indigenous people throughout the world are feeling the tensions created 
by a Eurocentric education system that has taught them to distrust their Indigenous knowledge system, their elder's wisdom and their own learning spirit" (Battiste, 2013, p. 25). In the end, with all of these factors at play, high school was not a pleasant place for me.

\section{Remembering Jake}

As I write about these past memories of my early teaching experiences and my own high school experience, I am drawn back to a moment with a student, Jake. Within this story is the whisper of true learning and an awakening I wish to share. Jake was a young man who was always arriving late for my morning Period One class, which started at 8:35 a.m. He would walk into my room loudly and nonchalantly, or sometimes quietly depending on his mood, and slide into his desk, almost without me noticing. He often wore a leather coat with a bunny hug and white runners. I remember his hair always being wet and combed back. He almost always had a blank expression on his face, and rarely did he look happy. Now that I think back on it, my thoughts at the time were that his lateness and his attitude were not my issues to deal with; I was not his counselor, nor his therapist! But I did want him to be on time, which added to my constant annoyance and need to be in control.

According to researcher Pedro Noguera, as quoted by Gebhard (2013), "...racial disparities in school discipline and achievement mirror the disproportionate confinement of racialized people, and ... students most frequently targeted for punishment in school often look like smaller versions of the adults most likely to be targeted for incarceration." As a means of disciplining Jake, I remember saying, "Jake, you are always late, and when you're late, you don't know what you're doing and you're wasting your time because you never do anything. I sometimes wonder what is even the point!!?" I said this out loud and I used him as an example for the other students. He never did pass my class nor did he ever take it again. I thought at the time, "That is fine with me." It was not.

I still remember that event in my life like it was yesterday because it was a lifechanging moment for me, one that I continue to regret. It caused me to ask myself what kind of teacher I was going to be. Up until then I had forgotten. Jake had given me a "whisper of true teaching and learning." This beautiful young man was of Indigenous descent, nêhiyâw/Cree or Métis. He, like other boys at his age, had a slick and arrogant "I am too cool for you" attitude that, I have learned with experience, is just how many boys are. I also know now that behaviors or ill- intentioned actions are always about something deeper. 
Why was I choosing to be indifferent at that time? Why was I not wanting to see the real Jake for who he was? Why was I so focused on the behavior? Now I know better; that was not acceptable. I "pushed" that young man out of my class and maybe even out of school because of my attitude, misguided assumptions, judgment, and false sense of superiority. The way I handled that situation was what I learned from my teachers years earlier when I was a student. What I recognize now is that I was unconsciously being discriminatory and racist to someone of color, someone like me, and that it was normalized to do so. As Ladson-Billings states, "Because it is so enmeshed in the fabric of our social order, it appears both normal and natural to people in this culture" (cited in Parker, Dehyle, \& Villenas, 1999, p. 12). The racism that is embedded in Canadian institutions (Laroque, 1989) is just as normalized in school culture.

I remember my English teacher humiliating me in front of a class of more than 30 students. He ridiculed me for always being five minutes late, saying to me that because I was always five minutes late, I would never amount to anything or succeed in anything. In that moment, I remember distinctly my feelings being hurt, I felt tears swell up, and anguish fueled my body. I was paralyzed wondering what I should do. Should I go sit down or should I leave? I stood there for a moment at the door and then stepped backed and closed the door. I never went back to that class and I was on the verge of quitting school that year because of my English teacher. He made me feel inadequate, like I was not good enough to even be in his classroom. His judgmental and ignorant behavior toward me caused serious emotional damage. It reminds me that what happens in our early adolescent stays with us for a lifetime. I sometimes wonder how many young men and women had he done that too? And then here I found myself, standing in the place of teacher, and doing the very same thing.

I believe it is because I did not understand all the social structures of mainstream education that come with being a teacher, and the pedagogies of the profession, that I was going through the motions of something deeper and subtle in an institution that perpetuates racism and discrimination. Berlak (as cited in Boler, 2004) states in her research findings:

Most graduates of teacher education programs were not prepared to deal with the realities they would face as teachers of African American, Latino, Asian immigrant, and poor children. She was convinced that many of those entering the profession were more likely to contribute to the destruction of these children than to their academic and personal growth and power. (p. 126) 
I have to agree. In the beginning I thought school was a safe and a neutral place, but I learned that this was not really the case. It was not a safe and neutral place for me, nor was it for Jake. I wonder if it is for any Indigenous students? Gebhard (2013) states, "By assuming that classrooms are neutral, apolitical spaces, schools risk pushing the same colonial agenda that Aboriginal education was founded on." As an Indigenous, nêhiyâw woman and educator, I struggled and grappled with a lot of the practices of mainstream education. I was getting pulled into curricula that did not resonate with me. Over time I learned that the school's expectations were mirroring the Ministry of Education's mandate, which not only added extreme pressure, but also a sense of pressure for conformity. Furthering this disposition was the classroom environment, which was seemingly cold and uninviting. Even as a student it was unfamiliar for me. For Jake, I am sure it was much the same way.

There was such a disconnect between who and what I was and what I was expected to teach. I remember walking into the English department room and looking over the novels, wondering where the literature was that was written by Aboriginal authors, as we lived in Canada, a country with a strong First Nations presence. We had a great number of literary authors and poets, so surely that was not the problem. When I did engage my students in experiential learning, taking them outside the walls of the school's yellow brick building, I remember questions being asked of me by my teacher colleagues, "Where is that in the curriculum?" I thought that after receiving my Bachelor of Education degree, I could teach my students what was relevant to my existence as an Indigenous person and to society's existence, but it wasn't like that. Not only were my colleagues questioning my class syllabus, but sometimes students were too, especially if they were white and the context of the lessons seemed unknown and unrecognizable. I did not have much say as to where I was going to teach, what I was going to teach, and for how long. I recall my thoughts as a beginning teacher:

My childhood was good, although I had lost my mother, it was stable. My life in the city as an adolescent was much different, but it did not mean I could teach and counsel these particular "at-risk" children. Because I was First Nations, it was thought that I could teach Aboriginal students better for some reason. But I knew I lacked experienced, counseling skills, behavior modification skills and social services procedures. (Daniels-Fiss, 2005, p. 12)

I remember I was mainly assigned to schools that were highly populated with Indigenous students. However, I did not really question these notions until much later in my teaching career. At the time, as a beginning teacher, I was in survival mode and I was imitating the teachers around me to try and live out the role of teacher. 
As I was struggling with my own career, trying to stay above water, I just did not have the capacity to understand where Jake was coming from or from what conditions. I was also learning to be a "white" teacher in the midst of chaos; I was racializing my own kind unconsciously, and I was turning into someone who saw color. What was I doing? Because racism is blended into the school system, I picked up unfavorable teaching practices and it was only my second year in the profession. "There is racism in school systems which can be traced back to the Euro-Canadian interpretation of history, an interpretation that has been uncritically transmitted in the education system" (Larocque, 1991, p. 73). I knew I had to do something differently, because past memories of my own education all flooded back to me through my experience with Jake. I knew this was not who I was; this was not where I began. This is not who I wanted to be.

\section{Moving Backward to My Childhood}

I needed to go back to my beginnings as an individual of my Indigenous heritage, a nêhiyâw, from a small Reserve two hours north of the city. In my home community, growing up on the Reserve, we referred to each other as Cousin or Friend when we addressed each other. It was also Brother or Sister, if we were first Cousins. Our ties of kinship were persistent in our families. The majority of the teachers, assistants, and other employees were also nêhiyâw in my Reserve school. A stream of activities were offered that were cultural, language based, and relevant to our existence. This teaching was vastly different than my education in the city.

In my upbringing, as I was raised by my grandparents, I saw my grandparents' role model of faith, hard work, and love. I saw integrity and pride in their work and they instilled this in me. I wanted to emulate this in my own life. I saw my grandfather pray daily, either through meditation, holding sweet-grass, ${ }^{2}$ or kneeling at the foot of his bed, a combination of spirituality and Catholicism known as syncretism, or "a blend of two belief systems. I was raised to respect aspects of both these faiths" (Daniels-Fiss, 2005, p. 3).

One evening, as a child, I watched my grandfather for a long time while he prayed. I am sure he must have sensed me standing and watching, as his prayer seemed unusually long compared to other times. When he was done, I asked, "Grandpa, what are you doing?" He replied that he was "talking to god." I asked, "About what? Who is god?" My grandfather replied that God was the all-knowing spirit, and that he was asking to be watched over by God, protected, guided, to have a good life, and for our family to be well. He told me that I should pray too, every day, and ask for wisdom, knowledge, and guidance... which I have, and continue to do to this day. Prayer is an important practice in my life as a nêhiyâw because it reminds me to be grateful 
for who I am and what I have. It is one of those essential teachings of the tipi ${ }^{3}$ or the medicine wheel ${ }^{4}$ and it makes me pause for a moment and breathe in the present. For nêhiyâw people, and other traditional Indigenous nations, the tipi and medicine wheel teachings are symbolic of life and of how we go about our journey in acceptance. These teachings are always about practicing to be a better human being. As one example, practicing being in the moment was a teaching I learned at a young age. It is about letting go of control and not worrying about tomorrow or being concerned with the past. It is a fresh start continuously. The Sacred Tree (Lane, Bopp, Bopp, \& Brown, 2003) illustrates this fresh start:

It is in the east of the medicine wheel that all journeys begin. When a path is new, it totally occupies our attention. Our sights are focused on the next few steps. One of the most important gifts to be acquired in the east is the capacity to focus our attention on the events of the present moment. As young children we knew instinctively how to do this. When as children we watched a beautiful butterfly or examined any interesting new aspect of the world, we were completely absorbed by what we were doing. (p. 45)

Because prayer is one of my most important teachings of our people, I have learned to pass on this teaching to my own children and to my students around me. Prayer is the center of our nêhiyâw and Indigenous ceremonies and our life. Our customs are based on this ceremony because we believe we are spiritual beings having a physical experience. I have heard this said time and time again. Ceremonies are a form of acknowledgment and connection to the spirit world, an acknowledgment that we are all one. The custom is that the ceremony is repeated because we know we are not in control of our lives. "Cree people believe they do not own their lives, so what lies ahead is unpredictable" (Daniels-Fiss, 2005, p. 50).

When I was little, my grand parents took me everywhere. This, too, was a value of my family. We often visited old people. We traveled from our Reserve to my grandmother's Reserve. I had many other grandparents that I referred to in the nêhiyâw way of life, as we do not have one set of grandparents for each parent, but many. My grandparents' brothers and sisters are also my grand parents. When visiting, food was an essential item which was always offered, even when people where in the middle of doing something. Everything was stopped to visit with one another and to eat. There was always "time" to engage in this act of relationship and sharing. My grandparents always went away with parting gifts or vice versa; they gave away gifts as well. My grandmother sometimes gave away her quilted blankets that she made by hand, out of a gesture of good will. My grandparents also gave other things such as berries from a summer harvest, plants like 
red willow, ${ }^{5}$ rat-root, $^{6}$ sweet-grass, and sometimes bear grease ${ }^{7}$ as gifts. I saw this act of good will firsthand, which instilled a sense of generosity and sharing deep within me. Although we did not have much, there was always something to give.

Because food was a sacred gift, there were many customary teachings that went along with it. In our own home it was always offered to guests as a sign of respect. Food was never wasted or thrown away, or left out on the counter or table overnight. Leftovers were nonexistent because we had such a large family. Food was the center of ceremonial celebrations as well, like feasts, which were common in my home community while I was growing up. There are protocols with having and giving a feast, which is given for all kinds of reasons: the coming of a new season, a new baby, or a memorial. Our lives were centered around food.

In the summer we planted our own potato garden as a family, and sometimes turnips and carrots as well. It was by no means a little family garden; it was a lot of hard work. As a result, I received an appreciation for the earth's soil and what she could grow; it was fascinating to pull food out of the earth! As for meat, sometimes our uncle would go hunting for a moose or two throughout the year and share that with us, which was always a treat. We would also pick blueberries, raspberries, and occasionally even cranberries during the summer and preserve them through canning, eating them only on special occasions. Gardening and collecting our own wood and water were all essential teachings that fostered respect, independence, and cooperation. Prayer and faith went hand in hand with food and celebrations. All of these teachings were sacred, instilling in us as children a strong sense of relationship with each other and the land.

In my Reserve school in my home community, some of the relevant teaching moments included plenty of opportunities to experience outdoor activities, like learning to fish and or track rabbits with the use of snare wire. As we engaged in such activities, we raised questions such as, "Where do rabbits live?" and "Why do they turn white in the winter?" The teacher made room in our school day to go out and explore the land. To do this together as a group made it even more memorable; the teacher was coming into our space, validating who we were as nêhiyâwak children. It also made our existence relevant to the land and to the place that we lived.

"Both my grandparents gave me a foundation of Cree ways... we have our own maps of teachings and meanings" (Daniels-Fiss, 2005, p. 48). Although diminished by cognitive imperialism (Battiste, 1986), the knowledge is still there, often revealed to us in the form of stillness, silence, prayers, and dreams, when we are actively searching for our own stories, answers, and pathways (Daniels-Fiss, 2008). 


\section{A Youth in the City}

As a teen, wanting to experience life in the city, I moved away from my home community and the care and guidance of my grandparents for a more tumultuous existence. Life was sometimes difficult, unpredictable, and exciting. Not only was I living with assignments that were looming over my head, but I was also dealing with a lot more....and the familiarities of home did not exist in the city. It was during the late 80 s and early 90 s that I moved to the city of Saskatoon. While attending high school, the classrooms were not filled with other Indigenous students, rather there were just two or three of us in sporadic pockets throughout the school. We took comfort in each other's presence, with the fact that we were not alone in the blanket of whiteness.

Jake was dealing with the same issues I was, just 10 years later. In his mainstream education, the nêhiyâw teachings were not understood, not even by me in that time and place. In the hierarchical system in which I was teaching, the values of the tipi or medicine wheel were not being lived. In fact, the school system was perpetuating a form of colonization. Gebhard (2013) stated:

The assumption that the education system today is devoid of its oppressive and violent past unfairly lets schools off the hook. Links between education and incarceration for Indigenous people in Canada are rarely made beyond pointing out that many Aboriginal people in custody are under-educated, often without high school diplomas.

Jake reminded me that I had forgotten what it was like growing up in the city, living in borderline poverty conditions, in an unstable home situation. I had forgotten what it was like not getting enough sleep the night before because there was a party going on in my living room, what it was like being awakened by loud music or encouraged to come and join the party. Worse, I had forgotten what it was like to be worried about my safety. I had forgotten what it was like to be peer pressured and coerced into breaking the law or witnessing others break the law. I had forgotten what it was like to grow up with circumstances that are beyond a young person's control. I had forgotten what it was like to be humiliated by the teacher in front of a class of students. Given my childhood on the Reserve and the teachings of my grandparents and people, I remained in culture shock throughout my whole existence and experience in high school. Was Jake living in a state of culture shock too? 


\section{Present Moment}

In my present moment, a student walks into my class; she just "pops in" a half hour late. She has missed over a week of school. My instinctive reaction is to be disappointed and dismayed, but then I breathe and respond in caring intentions. I casually say "Hi" and make a joke that I don't recognize her. She reacts shyly and responds that she has been "busy." I reply, "Busy, huh? Well, I am glad that's over and I am glad you are here; now let's catch up!" I am calm and relaxed. I go over past assignments and I make time for her.

I do not react harshly because of my epiphany with Jake, 10 years ago in my second year of teaching. My epiphany caused me to go back to my origins, to my childhood upbringing on the Reserve, and to ask myself,

What kind of teacher do I want to be? How was I taught? Who were my teachers? How can I incorporate into my identity as a teacher the other roles that I play, such as mother, auntie, sister, and, most importantly, granddaughter? What do these roles have in common with being a teacher, a great teacher?

As my grandparents raised me with love, compassion, and respect, they never made me feel like I did not belong. They always showed me patience and guidance and role modeled what was expected of me. Their love was never conditional. Couldn't I instill all of these values too as an educator? The answer is "yes."

My values are no longer conflicted. Who I was as a beginning teacher right out of college no longer exists. I am no longer emulating the qualities of the white teachers I had as a student nor am I perpetuating the colonial nature of the educational system. I do not believe my upbringing is a negative or a deficiency, as I was taught to believe as both a student and a teacher in the education system. I do not believe that Indigenous students should be unsuccessful or should fail because of culture.

The belief in twentieth-century social analysis about the incommensurability of different cultures encourages a trivializing of the impact of colonial oppression by attributing the effects and the conditions of oppression to this very factor of incommensurability. In the example of aboriginal people, effects of oppression are cast as 'value conflicts' between white and Indian cultures, suggesting that inequality is inevitable, and merely an effect of different orientations to work, education, and family. (St. Denis, 2009, p. 168) 
In order for me to be comfortable and to find a secure place in my mind and soul as a teacher, I needed to be proud of who I was and what I could offer. As a result of my experience with Jake a decade ago, I changed and unlearned what I was taught in Euro-mainstream high school and in my first degree in college. I went back to the practices and customs of my grandparents and community. I returned to building the relationships that are instrumental in being a great teacher.

There is an urgent need to change the well-rehearsed and scripted story of school (Pushor, 2007). I know that streaming our Indigenous students into categories of race or heritage is discriminatory. I know that the content of lessons has to relate to the student. I know that there needs to be more visible Indigenous educators and other Indigenous personnel involved in our schools. I know that sitting in rows and reading out of textbooks is killing the creative spirits in my students and, just as important, in me. Most importantly, I know that being in the moment, being spontaneous and fascinated about what is being learned in class, makes me realize that teaching has to be animated and alive. For me, this is what parallels the medicine wheel and tipi teachings, being in the moment and fascinated and full of love!

Rejecting the textbooks and the questions at the end of each chapter, I relearned the art of storytelling. This is a teaching method I learned unknowingly as a child and have come to perfect as a teacher. I relearned how to teach through experience, collaboration, and demonstration. I created opportunities for engagement and learned to listen to my students. It was not about perfection but learning to be better at these skills and not afraid to learn from and to admit mistakes. Teaching is always learning and always growing.

When I think back to my beginnings years as a teacher, I see that I have learned many lessons. Some of them have been painful, as Jake's was. I think about who I am now and I see that I have grown from my lessons. I have returned to the teachings of the many kêhtêyak, our old people, in my life and most importantly though my grandparents' Indigenous ways of knowing and being. Through all of these lessons, I have learned to be actively responsible for my learning and to rethink how we do education for all students. I know that we can no longer label Indigenous students as culturally different because of their heritage; this only leads to more inequality.

This objectification of culture also suggests that culture is something to be 'lost' and 'found.' It is as if people are no longer agents; culture happens to them. A notion like 'cultural determinism' then becomes possible. Cultural determinism has been used 
to justify racism; hence the notion of 'cultural racism' that becomes another way to justify discrimination. (St. Denis, 2009, p. 169)

I am truly grateful for Jake. It is because of this whisper of true learning that I awoke to the cycle of racism and discrimination and its embedded existences in our schools and decided to do something about it. I wanted to learn how European systems operated and to what extent. I am grateful that I awoke to who I was and to who I was meant to be because it is what has led me to where I am now. Much work remains to bring balance, equality, and a respectful co-existence in our schools. I am ready to forgive, willing to collaborate, and happy to teach. I see my nêhiyâw values and beliefs as an expression of my Indigenous knowledge and identity. I have something to offer. I have purpose, however large or small, that I help encourage and instill in my Indigenous students and my family. It is not about my culture, because I am more than my culture. It is because I am Cree. It is because I am a nêhiyâw that I am unique in all ways: historically, politically, educationally, and linguistically.

\section{Notes}

1. Also known as the Cree language. As this article explores Indigenous identity, I will use Indigenous terms for naming language, places, and people. It should be noted that in the nehiyaw language, the Roman Standard Orthography uses only lower case letters for all Cree words, regardless of conventions in English to capitalize names, places, and proper nouns. For further reference, see the work of Jean L. Okimasis and Arok Wolvengrey, How to Spell It in Cree (2008).

2. Sweet-grass is a plant that grows throughout the prairies. It has a purple root and a distinct smell. It is harvested during the summer months to be used as incense that purifies the nehiyaw mind, body, and spirit through an act of prayer.

3. Tipi teachings refer to family values, such as love, respect, faith, and so forth. There are 15 common values of the tipi, also referring to our values of the home in modern times.

4. Medicine wheel is the four quadrants of our being, referring to the emotional, spiritual, mental, and physical aspects of our nature and always practicing to be aware of these-balanced as a human being. 
5. Red willow is used for many things. The bark is used as a medicine or an additive to tobacco, or a purification cleanse. It is also used in practical ways such as to make red willow basketry.

6. Rat-root is a plant that grows in marsh-like areas or lakes, rivers, and streams. It is harvested to be used as a medicine that can either be made into a tea or chewed.

7. Bear grease is a balm to be used as a healing medicine for sore muscles, skin problems, and a remedy for hair thickness and health.

\section{References}

Battiste, M. (1986). Micmac literacy and cognitive assimilation. In J. Barman, Y. Hebert, \& D. McCaskill (Eds.), Indian education in Canada: The legacy (pp. 23-43). Vancouver: University of British Columbia Press.

Battiste, M. (2013). Decolonizing education. Saskatoon, SK: Purich Publishing Limited.

Berlak, A. (2004). Confrontation and pedagogy: Cultural secrets, trauma, and emotion in anti-oppressive pedagogies. In M. Boler (Ed.), Democratic dialogue in education: Troubling speech, disturbing silence (123-144). New York: Peter Lang Publishing.

Daniels-Fiss, B. (2005). My journey of learning the Cree language. Unpublished Master's Project, Department of Educational Foundations, University of Saskatchewan, Saskatoon, SK.

Daniels-Fiss, B. (2008). Learning to be a nehiyaw (Cree) through language. In Z. Bekerman \& S. MacPherson. (Eds.), Diaspora, Indigenous, and minority education, 2(3), 233-245.

Gebhard, A. (2013). Pipeline to prison: How schools shape a future of incarceration for Indigenous youth. Retrieved from: http:// briarpatchmagazine.com/articles/view/ pipeline-to-prison.
Ladson-Billings, G. (1991). Just what is critical race theory, and what's it doing in a nice field like education. In L. Parker, D. Deyhle, and S. Villenas (Eds.), Race is... race isn't: Critical race theory and qualitative studies in education, 7-30. Boulder, CO: Westview Press.

Lane, P. Jr., Bopp, M., Bopp, J., \& Brown, L. (2003). Sacred tree (3rd ed.). Lethbridge, $A B$ : Four Worlds International Institute for Human and Community Development.

Larocque, E. (1991). Racism runs through Canadian society. In O. McKague (Ed.), Racism in Canada, 73-76. Saskatoon, SK: Fifth House Publishers.

Okimasis, J., \& Wolvengrey, A. (2008). How to spell it in Cree: The Standard Roman orthography. Saskatoon, SK: miywâsin ink.

Pushor, D. (2007, Fall). Welcoming parents: Educators as guests hosts on school landscapes, Education Canada, 47(4), 6-11.

St. Denis, V. (2009). Rethinking cultural theory in Aboriginal education. In C. Levine-Rasky (Ed), Canadian perspectives on the sociology of education (163-182). Don Mills, ON: Oxford University Press Canada. 


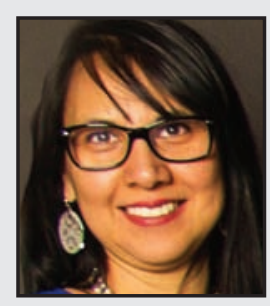

Belinda C. Daniels comes from the nêhiyâwak Nation of Saskatchewan. Her home community is Sturgeon Lake First Nations. Belinda has been an educator and consultant for 14 years, specializing in Aboriginal education. She now resides in Saskatoon with her family. She currently works for the Saskatoon Public School Division at a local high school and the University of Saskatchewan Languages Department. Belinda's interests are in research and engagement within her community and, particularly, in language revitalization and development. 